\title{
A 3D study on the amplification of regional haze and particle growth by local emissions
}

Wei Du ${ }^{1,2,12}$, Lubna Dada (iD ${ }^{2,12}$, Jian Zhao ${ }^{1,3}$, Xueshun Chen ${ }^{1}$, Kaspar R. Daellenbach ${ }^{2}$, Conghui Xie ${ }^{1,3}$, Weigang Wang (iD ${ }^{4}$, Yao He ${ }^{1,3}$, Jing $\mathrm{Cai}^{2}$, Lei Yao ${ }^{2}$, Yingjie Zhang ${ }^{1}$, Qingqing Wang ${ }^{1}$, Weiqi Xu ${ }^{1}$, Yuying Wang (D) $^{5}$, Guiqian Tang (D) ${ }^{1}$, Xueling Cheng (iD) Tom V. Kokkonen (D) $^{2}$, Wei Zhou ${ }^{1,3}$, Chao Yan ${ }^{2}$, Biwu Chu ${ }^{2}$, Qiaozhi Zha ${ }^{2}$, Simo Hakala (D) $^{2}$, Mona Kurppa ${ }^{2}$, Leena Järvi ${ }^{2,6}$, Yongchun Liu ${ }^{7}$,

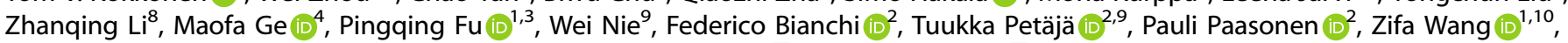
Douglas R. Worsnop ${ }^{11}$, Veli-Matti Kerminen ${ }^{2}$, Markku Kulmala ${ }^{2,7,9 凶}$ and Yele Sun ${ }^{1,3,10 凶}$

The role of new particle formation (NPF) events and their contribution to haze formation through subsequent growth in polluted megacities is still controversial. To improve the understanding of the sources, meteorological conditions, and chemistry behind air pollution, we performed simultaneous measurements of aerosol composition and particle number size distributions at ground level and at $260 \mathrm{~m}$ in central Beijing, China, during a total of 4 months in 2015-2017. Our measurements show a pronounced decoupling of gas-to-particle conversion between the two heights, leading to different haze processes in terms of particle size distributions and chemical compositions. The development of haze was initiated by the growth of freshly formed particles at both heights, whereas the more severe haze at ground level was connected directly to local primary particles and gaseous precursors leading to higher particle growth rates. The particle growth creates a feedback loop, in which a further development of haze increases the atmospheric stability, which in turn strengthens the persisting apparent decoupling between the two heights and increases the severity of haze at ground level. Moreover, we complemented our field observations with model analyses, which suggest that the growth of NPF-originated particles accounted up to $\sim 60 \%$ of the accumulation mode particles in the Beijing-Tianjin-Hebei area during haze conditions. The results suggest that a reduction in anthropogenic gaseous precursors, suppressing particle growth, is a critical step for alleviating haze although the number concentration of freshly formed particles (3-40 nm) via NPF does not reduce after emission controls.

npj Climate and Atmospheric Science (2021)4:4; https://doi.org/10.1038/s41612-020-00156-5

\section{INTRODUCTION}

Air pollution episodes, characterized by high aerosol particle loading, are one of the major environmental challenges in China as they profoundly impact the climate, visibility, and human health ${ }^{1}$. To investigate the sources, chemical processes, and other effects of severe haze pollution, extensive studies have been conducted in China, especially in Beijing-Tianjin-Hebei ${ }^{2-5}$, Yangtze River Delta ${ }^{6,7}$, and Pearl River Delta regions $s^{8,9}$. However, the formation mechanism of haze is still poorly understood owing to the multitude of aerosol sources, their spatio-temporal variability, and coupling of aerosols with atmospheric boundary layer processes ${ }^{10,11}$. Although primary particles emitted from traffic $^{12}$, cooking ${ }^{13}$, biomass burning ${ }^{14}$, and other sources contribute to haze, secondary aerosols formed in the atmosphere through gas-to-particle conversion were found to play an equal, or

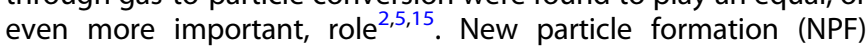
events, a major source of aerosol particles in the global atmosphere ${ }^{16-18}$, take place practically all over the world ${ }^{19,20}$, including in Chinese megacities where the concentrations of preexisting particles acting as a sink are exceptionally high ${ }^{21-23}$. NPF produces high number concentrations of small particles, which can act as seeds for the accumulation of secondary particulate mass via their growth ${ }^{2}$. However, in spite of its frequent occurrence, the role of NPF and particle growth in haze pollution has remained unexplained. Of particular interest in this regard is the connection between mixing processes, NPF, and haze within the atmospheric boundary layer.

We performed simultaneous measurements of particle number size distributions and chemical composition of sub-micron aerosols $\left(\mathrm{PM}_{1}\right.$, particles with aerodynamic diameter less than $1 \mu \mathrm{m})$ at ground level and at $260 \mathrm{~m}$ height in central Beijing during 2015-2017 (Supplementary Fig. 1 and Supplementary Table 1). Here, we explore the formation and sustained development of haze pollution associated with the growth of NPF-originated particles based on field observations, and then extend our findings into the Beijing-Tianjin-Hebei area using the Nested Air Quality Prediction Modeling System with Advanced Particle Microphysics (NAQPMS+APM model). Our observations provide evidence on the influence of the boundary layer structure on the formation and growth of particles of different composition and

\footnotetext{
${ }^{1}$ State Key Laboratory of Atmospheric Boundary Layer Physics and Atmospheric Chemistry, Institute of Atmospheric Physics, Chinese Academy of Sciences, 100029 Beijing, China. ${ }^{2}$ Institute for Atmospheric and Earth System Research/Physics, Faculty of Science, University of Helsinki, P.O. Box 64, 00014 Helsinki, Finland. ${ }^{3}$ College of Earth and Planetary Sciences, University of Chinese Academy of Sciences, 100049 Beijing, China. ${ }^{4}$ State Key Laboratory for Structural Chemistry of Unstable and Stable Species, Institute of Chemistry, Chinese Academy of Sciences, 100190 Beijing, China. ${ }^{5}$ School of Atmospheric Physics, Nanjing University of Information Science and Technology, 210044 Nanjing, China. ${ }^{6} \mathrm{Helsinki}$ Institute of Sustainability Science, University of Helsinki, Yliopistokatu 3, 00014 Helsinki, Finland. ${ }^{7}$ Aerosol and Haze Laboratory, Beijing Advanced Innovation Center for Soft Matter Science and Engineering, Beijing University of Chemical Technology, 100029 Beijing, China. ${ }^{8}$ College of Global Change and Earth System Science, Beijing Normal

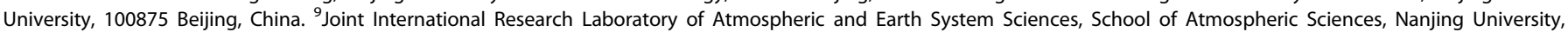
210023 Nanjing, China. ${ }^{10}$ Center for Excellence in Regional Atmospheric Environment, Institute of Urban Environment, Chinese Academy of Sciences, 361021 Xiamen, China. ${ }^{11}$ Aerodyne Research, Inc., Billerica, MA 01821, USA. ${ }^{12}$ These authors contributed equally: Wei Du, Lubna Dada. ${ }^{\circledR}$ email: markku.kulmala@helsinki.fi; sunyele@mail.iap.ac.cn
} 
size. Additionally, we found that even though the formation of haze associated with the growth of NPF particles occurs on a regional scale, the development of haze is more localized. Therefore, we hypothesize that local and regional sources act together to form haze by providing the elements required for its formation in slightly different portions. This, coupled with boundary layer mixing processes, makes the haze formation different at ground and above.

\section{RESULTS AND DISCUSSION}

\section{Boundary layer structure and haze amplification}

By observing the different behavior of the particles at ground level and at $260 \mathrm{~m}$, we hypothesized that a decoupling in terms of particle number size distribution and chemical composition between the two heights is probable. In more detail, we observed significant differences in the particle chemical compositions and number size distribution between the $260 \mathrm{~m}$ height and ground level, even when the mixing layer height $(\mathrm{MLH}$, altitude up to which we expect the atmospheric properties or substances originating from the surface to be mixed) was higher than 300 m, e.g. September 13-19, 2015 (Figs 1 and 2 and Supplementary Figs. 2 and 3). The ground data were measured within the roughness sublayer ${ }^{24}$, in which pollutant concentrations are influenced by local emissions and flow field is governed by individual buildings. The higher measurement height $(260 \mathrm{~m})$, instead, is typically situated within the well-mixed layer in daytime and even above the stable boundary layer within the residual layer at night. Vertical profiles of meteorological parameters (temperature, relative humidity $(\mathrm{RH})$, wind speed, and wind direction) are indicative of the boundary layer structure, showing a distinct roughness sublayer but also variability well above it (Supplementary Fig. 4). Previous studies have suggested that these fine atmospheric boundary-layer structures over Beijing influence the accumulation of particle mass ${ }^{25}$. We observed that differences in the particle number size distribution and chemical composition between the two heights became more obvious with an increasing $\mathrm{PM}_{1}$ loading at the ground level (Fig. 2 and Supplementary Fig. 5) ${ }^{26}$. Consistently, the evolution of the potential temperature showed that the atmospheric stability increased during the haze event (Supplementary Fig. 4). These results suggest that the atmospheric stability increased when the $\mathrm{PM}_{1}$ loading increased within the boundary layer, and this inefficient mixing of air between the two heights leads to a partial decoupling of the particle chemical composition and number size distribution between the ground level and $260 \mathrm{~m}$ during the haze formation and development.

To further confirm our hypothesis, we analyzed eight extreme haze episodes $\left(\mathrm{PM}_{1}>100 \mu \mathrm{g} \mathrm{m}^{-3}\right)$ during our measurement period (Supplementary Table 2). The haze event which occurred between September 13 and 19, 2015, is representative of all the other haze episodes during the observations (Figs 1 and 2). Prior to the haze episode, clean northerly air masses create favorable conditions for NPF. After that, only when the wind changed to a southerly direction, bringing more precursor vapors and moisture suitable for heterogeneous chemical reactions, we observed an initiation of haze development at both heights. Based on our observations, the chemical mass and size-resolved particle number concentration followed each other at the two heights during this initiation period. With the development of haze, particle growth rates were higher at ground level in comparison to $260 \mathrm{~m}$, which was likely due to a higher availability of condensing vapors and more suitable environment for particle growth at ground level. Consistent with this, the average $\mathrm{PM}_{1}$ mass concentration at $260 \mathrm{~m}$ was much lower than that at ground level. Even during the daytime of the haze accumulation period when the MLH was higher than $1000 \mathrm{~m}$, mass concentrations of chemical compositions showed pronounced differences between $260 \mathrm{~m}$ and ground level although the total $\mathrm{PM}_{1}$ mass concentrations were comparable at these two heights. This indicates the contribution of near-ground local sources, rather than regional transport, to secondary aerosol production. The continuous accumulation of aerosol mass at ground level was associated with the decreased vertical mixing after the initial development of the haze. The evolution of potential temperature profiles provides further evidence on that the atmospheric conditions became more stable day by day (Supplementary Fig. 4c). Haze stabilizes the atmosphere within the boundary layer, as the radiative heating close to the ground in the roughness sublayer is decreased due to attenuated solar radiation caused by the more efficient absorption in the upper haze surface $e^{10,11}$. This process decreases the ground-level air temperatures drastically when compared to higher altitudes. This causes an apparent decoupling of the two measurement heights as the conditions at ground level are more influenced by the local emissions. These results highlight the inadequacy of a single "MLH" to describe the vertical mixing within a complex urban environment ${ }^{27}$.

Enhanced growth and more severe haze through local emissions Additionally, we investigated whether it is possible for freshly formed particles to grow to haze-relevant sizes, and if so, what conditions are the most favorable for this to occur. Our postulation arose from the fact that an NPF event was observed prior to each haze episode, and these events showed signs of particle growth contributing to the accumulation of particle mass. We investigated 47 NPF events in more detail (Supplementary Table 1 and Supplementary Fig. 3). On 26 of the NPF events, the continuous growth of particles up to the accumulation mode led to an increase of particle mass (Supplementary Fig. 6). Moreover, particle growth was promoted by $\mathrm{RH}$ larger than 50\%, facilitating changes in particle phase states and secondary mass formation as shown in previous investigations ${ }^{28,29}$. Thus, freshly formed particles are able to reach mass-relevant sizes when the meteorological conditions are favoring their growth.

In our case study (September 13-19, 2015), we observed that the haze developed in three phases (Fig. 1). During the initiation period (September 13 midday-September 14 midday), the non-

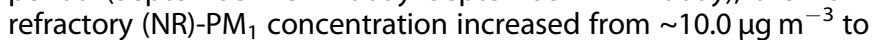
$\sim 90.0 \mathrm{\mu g} \mathrm{m}^{-3}$, having a similar chemical composition at both heights. The secondary aerosol mass accounted for $76 \%$ of (NR)$\mathrm{PM}_{1}$ at both heights and the mass fraction of secondary inorganic aerosols (SIA) increased drastically from $\sim 20 \%$ to $\sim 60 \%$, further confirming the significant contribution of secondary mass formation, especially for SIA (Supplementary Fig. 7). The unstable wind direction during this period indicated that the accumulation of particle mass could not be driven by regional transport. The simultaneous observation of NPF and continuous growth at both heights suggests that the growth of NPF-originated particles might be the important common source contributing to the increase of the particle mass. Although the accumulation mode particle number concentration was higher at $260 \mathrm{~m}$ (Supplementary Fig. 8), the lower mean diameter of particles there $(\sim 140 \mathrm{~nm}$ vs. $\sim 160 \mathrm{~nm}$ at ground level), attributed to the lower average growth rate $\left(5.2 \mathrm{~nm} \mathrm{~h}^{-1}\right.$ vs. $6.2 \mathrm{~nm} \mathrm{~h}^{-1}$ at ground level), led to a similar NR-PM $\mathrm{N}_{1}$ concentration as at ground level. During the initiation period, the daytime photochemical processes seemed to enhance secondary mass production $\left(\sim 8 \mu \mathrm{g} \mathrm{m}^{-3} \mathrm{~h}^{-1}\right)$ at both heights.

In the following 4 days, referred to as the accumulation period (September 14 midday-September 18 midnight), the mean diameter of particles remained relatively stable at the height of $260 \mathrm{~m}$, while at ground level particles continued growing to reach a mean diameter larger than $300 \mathrm{~nm}$. Consistently, the average $\mathrm{NR}-\mathrm{PM}_{1}$ of the whole accumulation period increased to $97.1 \mathrm{\mu g} \mathrm{m}^{-3}$ 


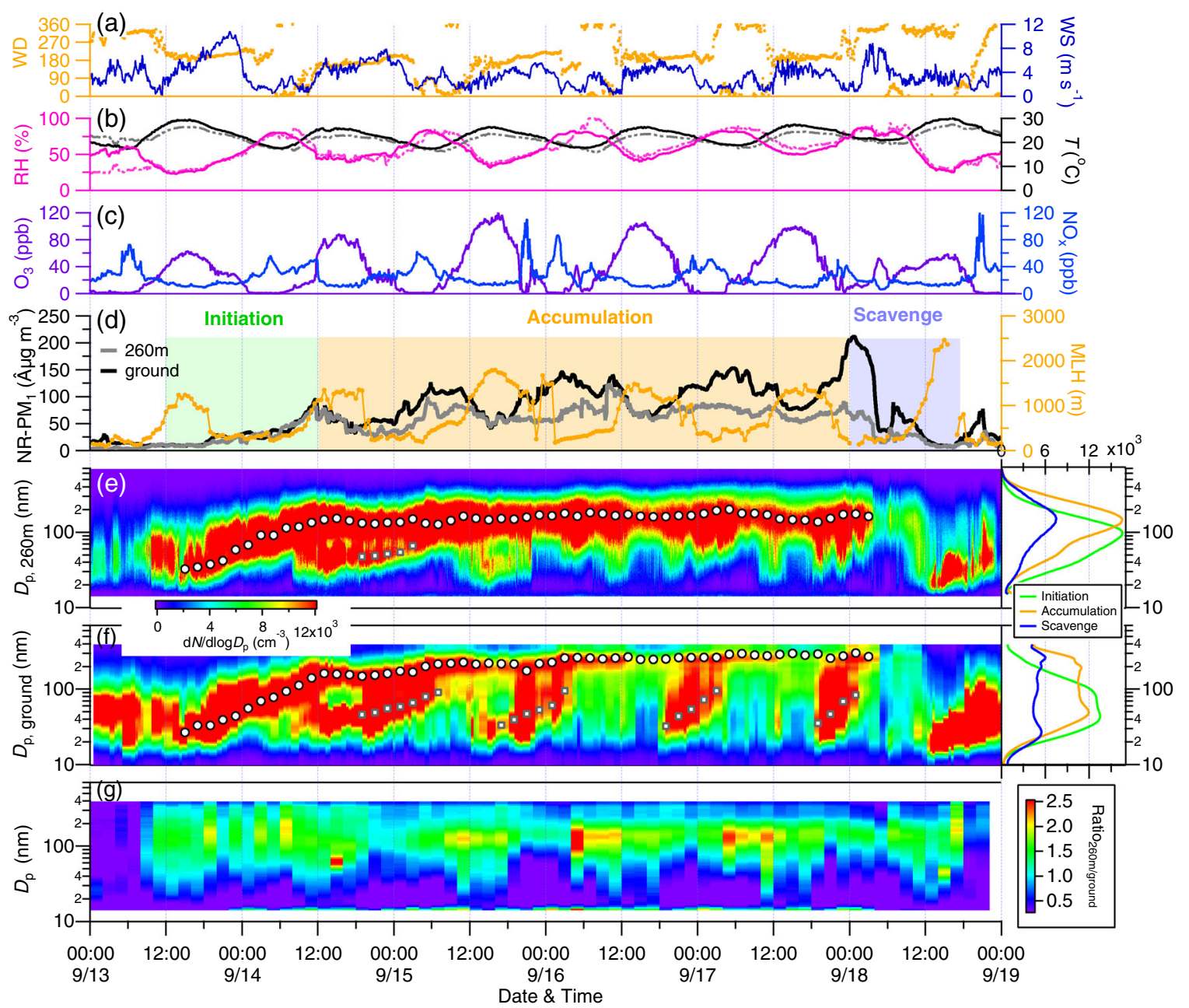

Fig. 1 Evolution of meteorological parameters, particle mass concentration, and size-resolved particle number concentrations during haze. Time series of a wind direction (WD) and wind speed (WS), b relative humidity $(\mathrm{RH})$ and temperature $(T)$, $\mathbf{c}$ ozone $\left(\mathrm{O}_{3}\right)$ and nitrogen oxides $\left(\mathrm{NO}_{x}=\mathrm{NO}+\mathrm{NO}_{2}\right)$, d mass concentrations of non-refractory submicron aerosols $\left.(\mathrm{NR}-\mathrm{PM})_{1}\right)$ and mixing layer height $(\mathrm{MLH})$ during a typical NPF event followed by a severe haze episode. The solid lines are the measurements at ground level and dash lines are measurements at $260 \mathrm{~m}$; e and $\mathbf{f}$ show the evolution of size-resolved particle number concentrations at $260 \mathrm{~m}$ and ground level, respectively. The right panels are the average size distributions of particle number concentrations for three periods, i.e., initiation (September 13 midday-September 14 midday), accumulation (September 14 midday-September 18 midnight), and scavenge (September 18 midnight-September 18 midday) as indicated in $\mathbf{d}$. In addition, the variations in geometric mean diameter (GMD) of regional new formed particles (circle) and urban new formed particles (cross) from log-normal fitting are also shown. $\mathbf{g}$ The ratios of size-resolved particle number concentrations between $260 \mathrm{~m}$ and ground level.

at ground level and only to $66.0 \mu \mathrm{g} \mathrm{m}^{-3}$ at $260 \mathrm{~m}$, a factor of 1.5 times higher at ground level. The difference in the mass loading and size distribution between the two heights, regardless of the high MLH $(>260 \mathrm{~m})$, suggests the contribution of local precursor emissions to larger growth at ground level and inefficient vertical mixing. This led to an increasing difference in the secondary aerosol mass concentration ( $90 \%$ of total mass difference, Supplementary Fig. 7) between the two heights with the progress of days. Most strikingly, the sulfate concentration increased $\left(0.39 \mu^{-3} \mathrm{~m}^{-3} \mathrm{~h}^{-1}\right)$ at ground level while remaining stable at $260 \mathrm{~m}$ over the course of 4 days (Fig. 2). Further analysis showed that both sulfate and secondary organic aerosol (SOA) were associated with the increasing mean diameter of the particle population (Supplementary Fig. 9), and that sulfate was probably the main contributor to the growth of seed particles originating from NPF. To further understand the possible pathways of sulfate production, we investigated similar pollution cases in winter 2016 (Supplementary Fig. 10). In the early stages, the concentrations of $\mathrm{SO}_{2}$ were comparable at the two heights. However, as the particles grew in size, the sulfur oxidation ratio (molar fraction of sulfate in total sulfur) increased, i.e. more $\mathrm{SO}_{2}$ was transformed to sulfate at ground level. This phenomenon was observed under a range of $\mathrm{O}_{3}$ concentration levels, and was enhanced by higher values of $\mathrm{RH}$, suggesting heterogeneous reactions facilitated by (1) higher $\mathrm{NO}_{2}$ concentrations associated with traffic emissions at ground level $^{30,31}$ or (2) higher $\mathrm{Fe}(\mathrm{III})$ and $\mathrm{Mn}$ (II) metal concentrations at ground level enhanced the catalyzed oxidation of $\mathrm{SO}_{2}$ by $\mathrm{O}_{2}$ (ref. ${ }^{32}$ ).

During the nighttime of the accumulation period, the difference in the particle mass concentration between the two heights became more significant, as $\mathrm{PM}_{1}$ increased more rapidly at ground level. On average, the nitrate concentration increased by a factor of $\sim 5$, from $6.6 \mathrm{\mu g} \mathrm{m}^{-3}$ in the late afternoon to $29.1 \mathrm{\mu g} \mathrm{m}^{-3}$ in the early morning at ground level, constituting more than $30 \%$ of total mass during the highest $\mathrm{PM}_{1}$ concentrations (Supplementary Figs. 7 and 11). This increase cannot be explained by temperaturedependent gas-to-particle partitioning, or evolution of the boundary layer height (which was mostly higher than $260 \mathrm{~m}$ ), as the mass formation rate was much slower at $260 \mathrm{~m}$. Not only nitrate but also SOA and ammonium concentrations showed 

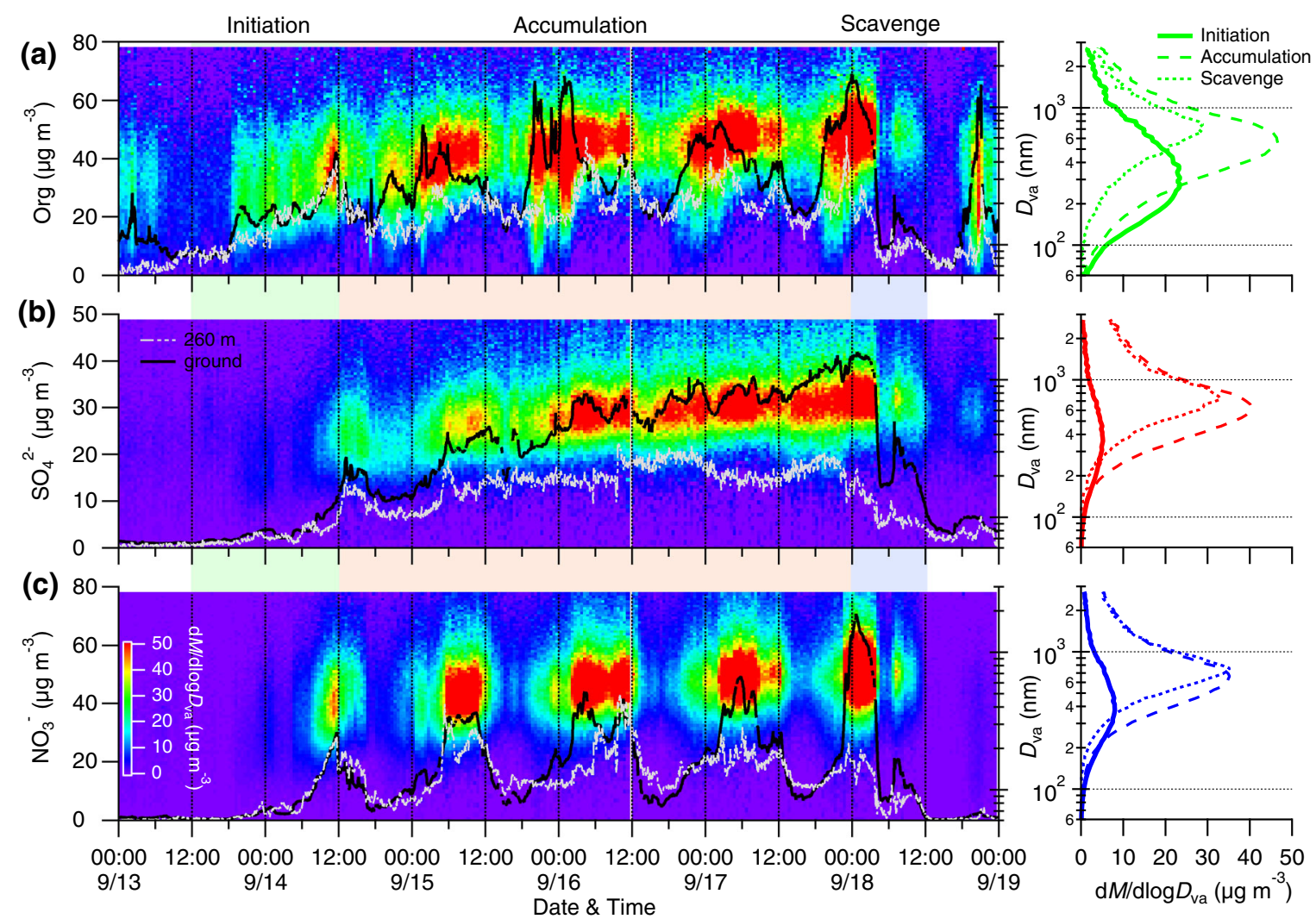

Fig. 2 Chemical compositions of submicron aerosols during haze pollution. The left panels show the evolution of total mass concentrations of a organics (Org), b sulfate $\left(\mathrm{SO}_{4}{ }^{2-}\right)$, $\mathbf{c}$ nitrate $\left(\mathrm{NO}_{3}{ }^{-}\right)$at $260 \mathrm{~m}$ (white line) and ground level (black line) during the typical NPF event followed by a severe haze episode. Size-resolved mass concentrations of Org, $\mathrm{SO}_{4}{ }^{2-}$, and $\mathrm{NO}_{3}{ }^{-}$measured at ground level by high-resolution time-offlight aerosol mass spectrometer are also shown. The right panels show the average mass size distributions of $\mathrm{Org}^{-} \mathrm{SO}_{4}{ }^{2-}$, and $\mathrm{NO}_{3}{ }^{-}$, respectively, for the three periods, i.e., initiation (September 13 midday-September 14 midday, 2015), accumulation (September 14 midday-September 18 midnight, 2015), and scavenge (September 18 midnight-September 18 midday, 2015).
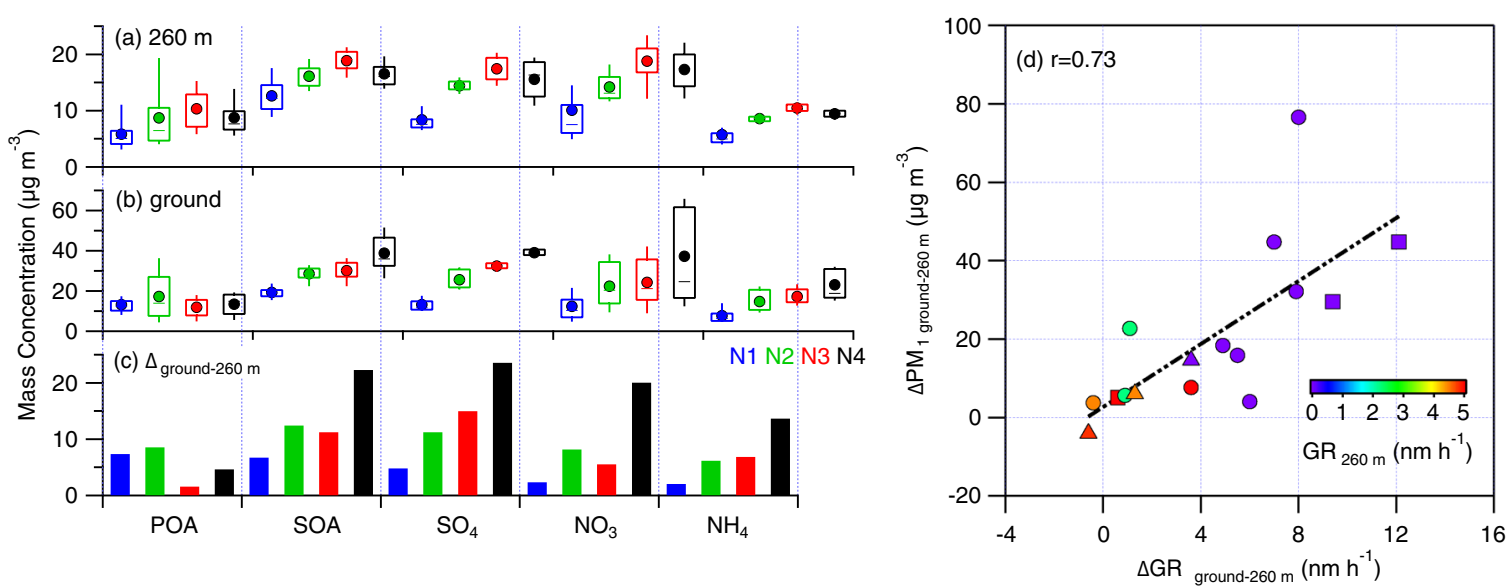

Fig. 3 Haze amplification and particle growth events. Primary organic aerosol (POA), secondary organic aerosol (SOA), sulfate $\left(\mathrm{SO}_{4}{ }^{2-}\right)$, nitrate $\left(\mathrm{NO}_{3}{ }^{-}\right)$, ammonium $\left(\mathrm{NH}_{4}{ }^{+}\right)$at $\mathbf{a} 260 \mathrm{~m}$ and $\mathbf{b}$ ground level during four nights (18:00-6:00) from September 14 to 18, 2015. N1, N2, N3, N4 were 18:00 September 14-6:00 September 15, 18:00 September 15-6:00 September 16, 18:00 September 16-6:00 September 17, 18:00 September 17-6:00 September 18, respectively. The mean (diamonds), median (horizontal line), 25th and 75th percentiles (lower and upper box), and 10th and 90th percentiles (lower and upper whiskers) are shown in the box. c The differences of average mass concentrations between the two heights $\left(\Delta_{\text {ground-260m }}\right)$. d Relationship between the differences of $\mathrm{PM}_{1}$ mass concentrations $\left(\Delta \mathrm{PM} \mathrm{M}_{1}\right.$ ground-260m $)$ between ground and $260 \mathrm{~m}$ versus those of particle growth rates $\left(\Delta \mathrm{GR}_{\text {ground-260 } \mathrm{m})}\right.$ in autumn 2015 (circle), winter 2016 (square), and summer 2017 (triangle). The points are colored by the particle growth rates at $260 \mathrm{~m}$.

differences between the two heights during nighttime, the concentrations being 13.2 and $7.2 \mathrm{\mu g} \mathrm{m}^{-3}$ higher at ground level, respectively. These results demonstrate the importance of secondary aerosol mass production associated with the particle growth at ground level, accompanied by the inefficient vertical transportation (Figs 1 and 3). On the first night of the haze cycle (September 14 to 15), growth of primary particles was observed at both heights. However, the faster growth at ground level $\left(3.4 \mathrm{~nm} \mathrm{~h}^{-1}\right.$ 
(a)

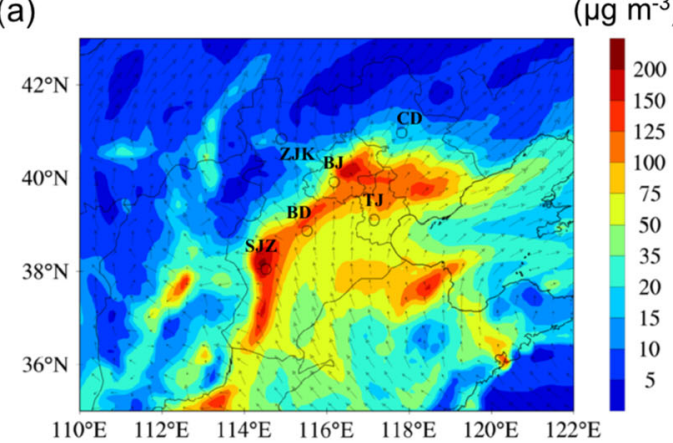

(b)

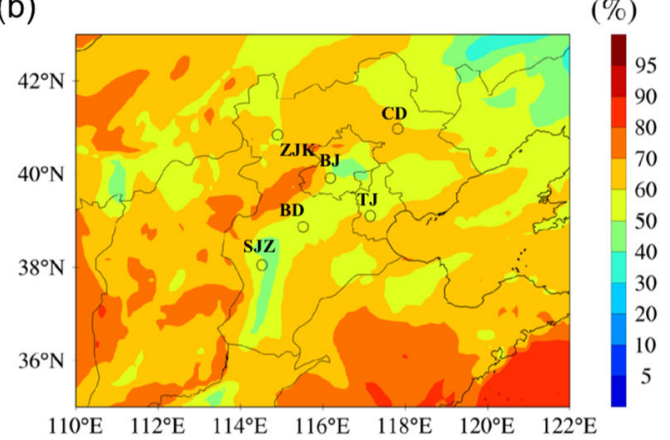

Fig. 4 Regional new particle formation and haze. Spatial distributions of $\mathbf{a} \mathrm{PM}_{2.5}$ mass concentrations and $\mathbf{b}$ fractions of accumulation mode particles from the growth of newly formed particles in Beijing-Tianjin-Hebei Area at 12:00 on September 14, 2015. The major cities of Chengde (CD), Zhangjiakou (ZJK), Beijing (BJ), Tianjin (TJ), Baoding (BD), and Shijiazhuang (SJZ) are shown.

at ground level vs. $2.3 \mathrm{~nm} \mathrm{~h}^{-1}$ at $260 \mathrm{~m}$ ) indicated stronger secondary mass production at ground level. In the later three nights (September 16-18), the growth rates were 7.0, 7.9, and $8.0 \mathrm{~nm} \mathrm{~h}^{-1}$ at ground level, respectively, and these events were not observed at $260 \mathrm{~m}$, which can be explained by increased atmospheric stability during nighttime and weaker vertical transport from the ground upward. Thus, higher concentrations of nitrate, ammonium, and secondary organics were observed at ground level.

We then investigated 22 nighttime growth events that occurred during the autumn 2015, winter 2016, and summer 2017 (Supplementary Table 3 ). The $\mathrm{PM}_{1}$ concentration was similar at the two heights when a particle growth event occurred at both heights, whereas it was much higher at ground level when a growth event was observed only at ground level. In addition, the differences in the $\mathrm{PM}_{1}$ concentration between the two heights increased with an increasing difference in the particle growth rate (Fig. 3d), confirming our results that the growth of locally emitted primary particles was the main reason contributing to more severe haze at ground level during nighttime. The high concentrations of SOA, nitrate, and ammonium at ground level decreased significantly during the afternoon due to evaporation of semi-volatile compounds and dilution caused by the boundary layer growth. These concentrations were even lower than those at $260 \mathrm{~m}$ because of the lower temperatures at $260 \mathrm{~m}$ suppressing the evaporative losses and stronger photochemical reactions at $260 \mathrm{~m}$ enhancing secondary aerosol formation, which further reduced the mass differences between the two heights.

The last phase of the haze cycle was characterized by a reduction of the particle mass concentration driven by changes in synoptic weather conditions. As a result, the average mass concentration of NR-PM 1 at $260 \mathrm{~m}$ dropped to $\sim 30 \mu \mathrm{g} \mathrm{m}^{-3}$. This removal process was even more dramatic at ground level, characterized by a slow drop in NR-PM $\left(213\right.$ to $148 \mu \mathrm{g} \mathrm{m}^{-3}$ in $3 \mathrm{~h}$ ), followed by a sharp decrease (148 to $35 \mu \mathrm{g} \mathrm{m}^{-3}$ in $1 \mathrm{~h}$ ) enhanced by the fast winds and associated mechanical turbulence and mixing.

Growth of NPF-originated particles contributes to haze on a regional scale

To further assess the contribution of particles from NPF, we employed the NAQPMS+APM model. The modeled fine particle concentrations $\left(\mathrm{PM}_{2.5}\right.$, particulate matter with diameter less than $2.5 \mu \mathrm{m}$ ) and measured $\mathrm{PM}_{1}$ concentrations (Supplementary Fig. 12) agreed well and the modeled particle number size distributions (Supplementary Fig. 13c) compare well with our in situ measurements (Fig. 1f) in Beijing. The evolution of the chemical composition and size distribution of submicron aerosols aloft indicate that haze associated with NPF and growth was formed on a regional scale. The regional scale, here, refers to the
Beijing-Tianjin-Hebei area as a whole, whereas the local scale corresponds to the urban-Beijing area. The NAQPMS+APM model confirmed that haze formed simultaneously in the whole Beijing-Tianjin-Hebei area (Fig. 4a and Supplementary Fig. 14). The simulated particle number size distribution in six cities (including Chengde (CD), Zhangjiakou (ZJK), Beijing (BJ), Tianjin (TJ), Baoding (BD), and Shijiazhuang (SJZ)) within this area showed similar variations, characterized by NPF followed by continuous growth (Supplementary Fig. 13). Haze was more severe in larger cities due to the higher abundance of gaseous precursors and the local growth events driven by increased population and urbanization. This result also indicates that although haze formation associated with the growth of NPF particles is a regional phenomenon, its development is more localized. In general, during the haze episodes, $\sim 60 \%$ of accumulation mode particles originated from the growth of newly formed particles in most polluted areas (Fig. 4b and Supplementary Fig. 15).

\section{Suppressing particle growth, a step toward reducing haze} formation

Overall, the NAQPMS+APM model together with observations from $260 \mathrm{~m}$ and ground level, representing regional conditions and the local environment, suggested that particle growth drive haze formation in the Beijing-Tianjin-Hebei area. In the initiation period, particles are formed from regional NPF events and grow further, leading to a simultaneous haze formation at both heights. Furthermore, the decreased vertical mixing in the atmospheric boundary layer allows pollutants emitted at ground level to be trapped within a small volume of air, creating conditions typical of a heavy air pollution episode earlier referred to as a "choking cocktail" by Kulmala ${ }^{33}$. Thus, coupled with less effective boundary layer mixing, the haze pollution at ground level is more severe than at high altitude during the haze accumulation period because: (1) particles originating from NPF continue to grow at ground level while their mean diameter remains relatively stable at a higher altitude; (2) local primary particles grow to larger size at ground level during nighttime (Fig. 5).

In order to reduce haze pollution in Beijing-Tianjin-Hebei area and in similar megacities, suppressing the growth processes of particles is crucial. In fact, emission control for gaseous precursors is an efficient scheme. We performed simulations on how emission reductions would affect haze development. In the sensitivity scenarios, emissions of both primary particles and gaseous precursors over Beijing-Tianjin-Hebei area were cut by 10\%, 30\%, and 50\% (Fig. 6 and Supplementary Figs S16-18). First, upon implementation of emission reductions, primary particle number concentrations would decrease substantially which leads to a reduction in background particle concentrations, a lower condensation sink collectively promoting the occurrence of NPF. Thus, the number concentration of secondary particles in the size 
range from 3 to $40 \mathrm{~nm}$ which originated from NPF would show an increasing trend. However, these small particles would not grow to larger sizes due to the lack of gaseous precursors for such growth. As a result,the number concentration of secondary particles in the accumulation mode is expected to be cut by $20 \%$ when the emissions were cut by $50 \%$. All in all, upon the implementation of the reduction of primary particle emissions in the Beijing-Tianjin-Hebei area, the NPF becomes more prominent, which would need further assessment of the relevant reductions in order to alleviate this process (see also Kulmala et al. $^{34}$ ). The impact of $10 \%$ reduction of emissions will be minor, yet, when emission cuts are higher than $30 \%$, both primary and secondary particles' concentration in the accumulation mode would decrease drastically, reducing mass accumulation and haze formation.

\section{METHODS}

\section{Experimental design}

The sampling site is located at the tower branch of the Institute of Atmospheric Physics (IAP), Chinese Academy of Sciences ( $39^{\circ} 58^{\prime} \mathrm{N}, 116^{\circ} 22^{\prime}$ E), which is a typical urban site located between the north third and fourth ring road in Beijing, and surrounded by residential areas and main streets

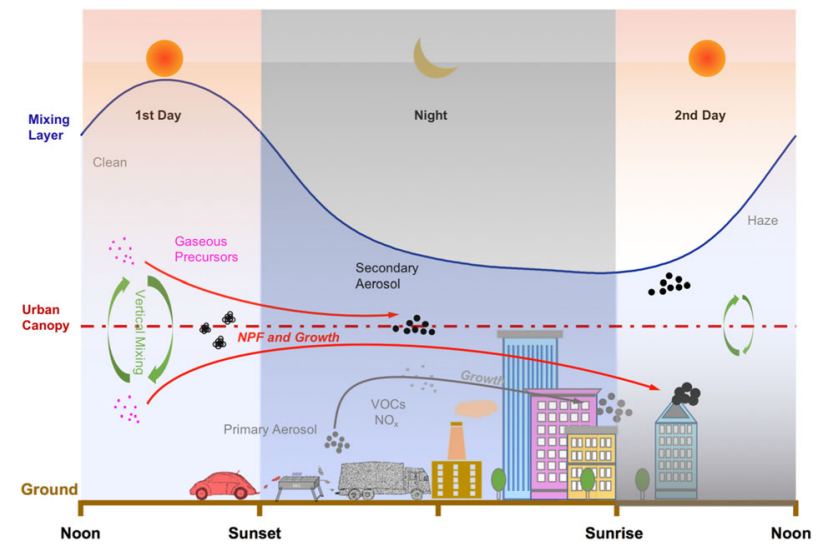

Fig. 5 Schematic plot to show enhanced particle growth by local primary emissions contribute to more severe haze at ground level. Blue line: Mixing layer. Red dash line: Urban canopy. Two main processes are illustrated here: 1) the growth process of particles originating from new particle formation (NPF) (red line with arrow). This growth process lasts for a longer time and reaches a larger size at ground level due to a higher availability of condensing vapors provided by local emissions. 2) the growth process of local primary particles at ground level (black line with arrow). These two processes and the less effective boundary layer mixing (green line with arrow) together lead to more severe haze at ground level.
(Supplementary Fig. 1). The detailed description of the sampling site was given in Sun et al. ${ }^{5}$.

We built a platform at $260 \mathrm{~m}$ on the Beijing $325 \mathrm{~m}$ meteorological tower (BMT) together with ground site to determine the vertical characteristics of meteorological conditions, gas pollutants, and aerosol particles, including mass concentrations, chemical compositions, and particle number size distributions. At $260 \mathrm{~m}$, all instruments were placed in two small containers with constant temperature controlled by two air conditioners. The instruments deployed were an Aerosol Chemical Speciation Monitor (ACSM, Aerodyne Research Inc.), a two-wavelength Aethalometer (AE22, Magee Scientific Corp.), a Scanning Mobility Particle Sizer (SMPS, TSI), and a suite of gas analyzers $\left(\mathrm{CO}, \mathrm{SO}_{2}\right.$, and $\mathrm{O}_{3}$ ). At ground level, a high-resolution time-of-flight Aerosol Mass Spectrometer (HR-ToF-AMS, Aerodyne Research Inc.), a seven-wavelength Aethalometer (AE33, Magee Scientific Corp.), a Scanning Mobility Particle Sizer (SMPS, TSI), and gas analyzers were deployed. Details on the operation of these instruments can be found in the Supplementary Methods.

Overall, three intensive campaigns were carried out during three different seasons, including autumn (August 22-October 1, 2015), winter (November 21-December 13, 2016), and summer (June 1-26, 2017) (Supplementary Table 1). Using chemically resolved particle densities (Supplementary Methods), measured particle number size distributions from the SMPS were converted into mass concentrations. The particle mass concentration derived from the SMPS were highly correlated with the total particle mass concentrations measured by the ACSM and Aethalometer (NR-PM $1+B C$ ) in autumn 2015 (ref. ${ }^{35}$ ), winter 2016 (Supplementary Fig. 19c), and summer 2017 (Supplementary Fig. 19d), suggesting the stable operation of these instruments and high quality of the data.

\section{Source apportionment}

We used positive matrix factorization (PMF) with the PMF2.exe (v4.2) algorithm to separate organic aerosols (OA) into different factors from different sources and processes ${ }^{26}$. At ground level, primary organic aerosol (POA) factors, including hydrocarbon-like OA (HOA) from traffic emissions and cooking-related OA (COA), as well as SOA factors including more oxidized oxygenated organic aerosol (MO-OOA) and less oxidized oxygenated organic aerosol (LO-OOA) were identified. The PMF results were validated by (1) spectral pattern comparisons with previously reported OA factors, (2) correlations with specific fragment ions and external gaseous and/or particulate tracers, (3) diurnal patterns, and (4) other diagnostic plots. The detailed evaluation of PMF results was given elsewhere ${ }^{26}$.

\section{Identification of NPF and growth events}

Previous studies show that particles at the high altitude above the urban canopy height are less affected by the local emissions ${ }^{26,35,36}$. Thus, to avoid the influence of local emissions, the classifications of NPF were based on the variations of particle number size distribution at $260 \mathrm{~m}$. Following from Maso et al. ${ }^{37}$, an NPF event was identified in our study when we observed a burst of particles as a new mode and their continuous growth both at $260 \mathrm{~m}$ and ground level. Besides, our model study which is in line with our classification is also used as aid to identify NPF events. These events were further separated into two different types of NPF (Supplementary Fig. 20),
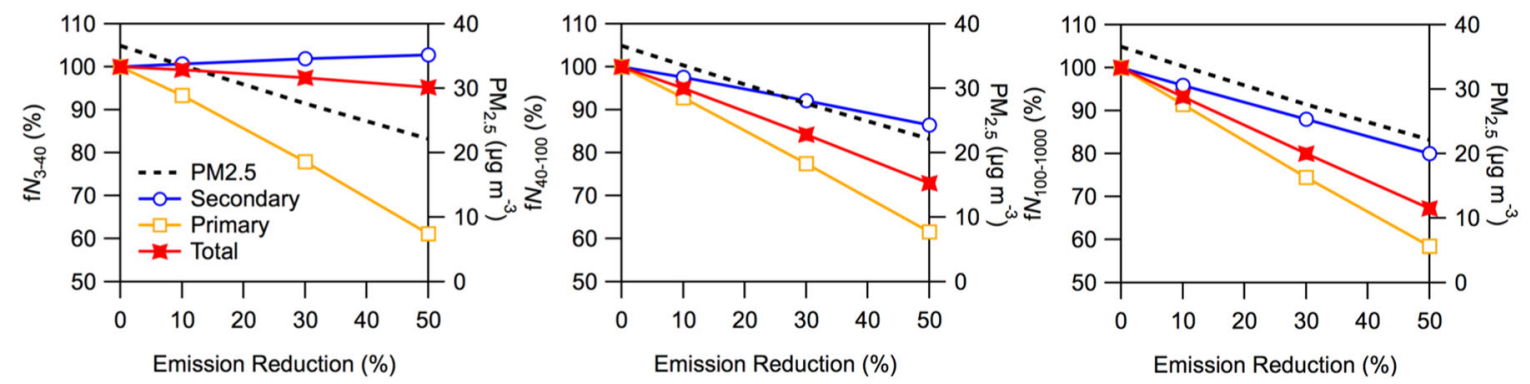

Fig. 6 The changes in particle number concentrations and $\mathbf{P M}_{2.5}$ resulting from emission reductions in the Urban Beijing in September, 2015. The percentage change in particle number concentration ( $f N$ ) is the ratio between particle number concentration after and in the absence of emission reductions. In the three sensitivity scenarios, emissions of all species including the gaseous precursors and primary particles over Beijing-Tianjin-Hebei areas were cut by 10\%, 30\%, and 50\%, respectively. The particles are categorized into primary which are associated with direct emissions, and secondary which are associated with new particle formation. 
for example, NPF-1 in Supplementary Fig. 20b and NPF-2 in Supplementary Fig. 20c.

The particle growth rates $(G R)$, representing the increase in geometric mean diameter $\left(\Delta D_{\mathrm{p}}\right)$ during the growth period of $\Delta t$, were calculated using the following equation:

$\mathrm{GR}=\frac{\Delta D_{\mathrm{p}}}{\Delta t}$

Condensation sink (CS) indicates how rapidly gaseous molecules are scavenged by pre-existing aerosol particles. It is calculated from the following Eq. $(2)^{38}$ :

$\mathrm{CS}=2 \pi D \sum_{\mathrm{i}} \beta_{\mathrm{Mi}} D_{\mathrm{p}, \mathrm{i}} N_{\mathrm{i}}$

where $D$ is the diffusion coefficient of the condensing vapor, $N$ is particle number concentration for diameter $D_{\mathrm{p}}$, and $\beta_{\mathrm{M}}$ is the transitional regime correction factor. The calculation of CS might be underestimated without considering ambient $\mathrm{RH}^{39}$.

\section{NAQPMS+APM model}

A three-dimensional (3D) model, NAQPMS $+\mathrm{APM}^{40}$, was used to elucidate the role of particle growth in haze pollution in urban Beijing. NAQPMS is the host model and APM is the microphysical module. NAQPMS has been widely used to study the air pollution and atmospheric chemistry ${ }^{41}$. APM in NAQPMS+APM is a revised version based on the version in GEOS-Chem ${ }^{42}$ The basic physical and chemical processes in NAQPMS+APM include horizontal and vertical advection, diffusion, dry deposition, gaseous chemistry, aqueous chemistry and wet deposition, heterogeneous chemistry, and equilibrium partition of nitrate and ammonium. In the microphysical module, the model explicitly calculates the condensation of sulfuric acid and low-volatility organic compounds and simulates equilibrium partitioning of semi-volatile species, including semi-volatile organics, nitrate, and ammonium. The model uses high-resolution sizebins, 40 size bins with dry diameters ranging from $0.0012 \mu \mathrm{m}$ to $12 \mu \mathrm{m}$, to calculate the size distribution of new particles formed through nucleation and subsequent growth. Internal mixing is assumed for secondary nucleated particles and primary particles are assumed to be composed of a seeding core and coating species. The secondary coating species on primary particles are explicit resolved. The model has the ability to precisely represent NPF process and separate the contribution of primary particles and secondary nucleated particles to particle formation. The model has been shown to be able to reasonably explain the formation of particle number size distribution in Beijing ${ }^{43}$ and to reproduce the particle number concentration over China ${ }^{44,45}$.

In our simulations, three nested modeling domains were used, with the first domain covering whole globe at $1^{\circ}$ resolution, the second domain covering east Asia at $0.33^{\circ}$ resolution, and the third domain covering eastern China at $0.11^{\circ}$ resolution. The boundary conditions of the child domain are provided by the corresponding outer domain. The model has 20 vertical layers and the top layer is at $20 \mathrm{~km}$. The meteorological fields input to NAQPMS+APM were produced by the Weather Research and Forecasting model (WRF). WRF was driven by Final Analysis (FNL) datasets from the National Centers for Environmental Prediction (NCEP) (https://rda. ucar.edu/datasets/ds083.2). The wind, temperature, humidity, and pressure fields were nudged to FNL data. Emission data input to NAQPMS+APM was an integrated dataset from a publicly datasets for the globe (https:// edgar.jrc.ec.europa.eu/htap_v2/index.php) and the multi-resolution emission inventory for China (MEIC) (http://www.meicmodel.org). The base year of global emission is in 2010 and MEIC is in 2015. Monthly-mean emissions are used in the model. In our study, four simulation scenarios, i.e., one base scenario and three sensitivity scenarios, were used. In the three sensitivity scenarios, emissions of all species over Beijing-Tianjin-Hebei areas were cut by $10 \%, 30 \%$, and $50 \%$, respectively. At IAP site in Beijing, the correlation coefficients of black carbon, organic matter, sulfate, nitrate, and ammonium between the base simulation and observation are $0.76,0.50$, $0.56,0.59$, and 0.6 , respectively. The mean bias errors of aerosol components are lower than $20 \%$.

\section{DATA AVAILABILITY}

The particle number size distribution, chemical composition, and auxiliary data are available upon request from the corresponding author Yele Sun: sunyele@mail.iap.ac.cn.

\section{CODE AVAILABILITY}

The codes are available upon request from the corresponding author Yele Sun: sunyele@mail.iap.ac.cn.

Received: 2 June 2020; Accepted: 16 December 2020; Published online: 18 January 2021

\section{REFERENCES}

1. Zhang, R. et al. Formation of urban fine particulate matter. Chem. Rev. 115, 3803-3855 (2015).

2. Guo, S. et al. Elucidating severe urban haze formation in China. Proc. Natl Acad. Sci. USA 111, 17373-17378 (2014).

3. $\mathrm{Ma}, \mathrm{Q}$. et al. Roles of regional transport and heterogeneous reactions in the PM2.5 increase during winter haze episodes in Beijing. Sci. Total Environ. 599-600 246-253 (2017).

4. An, Z. et al. Severe haze in northern China: a synergy of anthropogenic emissions and atmospheric processes. Proc. Natl Acad. Sci. USA 116, 8657-8666 (2019).

5. Sun, Y. L. et al. "APEC Blue": secondary aerosol reductions from emission controls in Beijing. Sci. Rep. 6, 20668 (2016).

6. Cheng, Z. et al. Long-term trend of haze pollution and impact of particulate matter in the Yangtze River Delta, China. Environ. Pollut. 182, 101-110 (2013).

7. Zhang, Y. J. et al. Insights into characteristics, sources, and evolution of submicron aerosols during harvest seasons in the Yangtze River delta region, China. Atmos. Chem. Phys. 15, 1331-1349 (2015).

8. He, L.-Y. et al. Submicron aerosol analysis and organic source apportionment in an urban atmosphere in Pearl River Delta of China using high-resolution aerosol mass spectrometry. J. Geophys. Res. 116 (2011).

9. Huang, X. F. et al. Characterization of submicron aerosols at a rural site in Pearl River Delta of China using an Aerodyne High-Resolution Aerosol Mass Spectrometer. Atmos. Chem. Phys. 11, 1865-1877 (2011).

10. Petäjä, T. et al. Enhanced air pollution via aerosol-boundary layer feedback in China. Sci. Rep. 6, 18998 (2016)

11. Ding, A. J. et al. Enhanced haze pollution by black carbon in megacities in China. Geophys. Res. Lett. 43, 2873-2879 (2016).

12. Kang, H. et al. Analysis of a long-lasting haze episode in Nanjing, China. Atmos. Res. 120-121, 78-87 (2013).

13. Zhang, J. et al. Chemical composition, source, and process of urban aerosols during winter haze formation in Northeast China. Environ. Pollut. 231, 357-366 (2017)

14. Cheng, Z. et al. Impact of biomass burning on haze pollution in the Yangtze River delta, China: a case study in summer 2011. Atmos. Chem. Phys. 14, 4573-4585 (2014).

15. Huang, R. J. et al. High secondary aerosol contribution to particulate pollution during haze events in China. Nature 514, 218-222 (2014).

16. Zhang, R., Khalizov, A., Wang, L., Hu, M. \& Xu, W. Nucleation and growth of nanoparticles in the atmosphere. Chem. Rev. 112, 1957-2011 (2012).

17. Spracklen, D. V. et al. Explaining global surface aerosol number concentrations in terms of primary emissions and particle formation. Atmos. Chem. Phys. 10, 4775-4793 (2010).

18. Dunne, E. M. et al. Global atmospheric particle formation from CERN CLOUD measurements. Science 354, 1119-1124 (2016).

19. Kulmala, M. et al. Formation and growth rates of ultrafine atmospheric particles: a review of observations. J. Aerosol Sci. 35, 143-176 (2004).

20. Chu, B. et al. Atmospheric new particle formation in China. Atmos. Chem. Phys. 19 115-138 (2019).

21. Kulmala, M. et al. Atmospheric gas-to-particle conversion: why NPF events are observed in megacities? Faraday Discuss. 200, 271-288 (2017).

22. Kulmala, M. et al. On secondary new particle formation in China. Front. Environ Sci. Eng. 10, 10 (2016).

23. Yao, L. et al. Atmospheric new particle formation from sulfuric acid and amines in a Chinese megacity. Science 361, 278-281 (2018).

24. Britter, R. E. \& Hanna, S. R. Flow and dispersion in urban areas. Annu. Rev. Fluid Mech. 395, 469-496 (2003)

25. Chan, C. Y. et al. Characteristics of vertical profiles and sources of PM2.5, P M10 and carbonaceous species in Beijing. Atmos. Environ. 39, 5113-5124 (2005).

26. Zhao, J. et al. Insights into aerosol chemistry during the 2015 China Victory Day parade: results from simultaneous measurements at ground level and $260 \mathrm{~m}$ in Beijing. Atmos. Chem. Phys. 17, 3215-3232 (2017).

27. Barlow, J. F. Progress in observing and modelling the urban boundary layer. Urban Clim. 10, 216-240 (2014).

28. Sun, Y. et al. The impact of relative humidity on aerosol composition and evolution processes during wintertime in Beijing, China. Atmos. Environ. 77, 927-934 (2013). 
29. Liu, Y. et al. Submicrometer particles are in the liquid state during heavy haze episodes in the urban atmosphere of Beijing, China. Environ. Sci. Technol. Lett. 4, 427-432 (2017).

30. Cheng, Y. F. et al. Reactive nitrogen chemistry in aerosol water as a source of sulfate during haze events in China. Sci. Adv. 2, e1601530 (2016).

31. Wang, Q. et al. Vertically resolved characteristics of air pollution during two severe winter haze episodes in urban Beijing, China. Atmos. Chem. Phys. 18, 2495-2509 (2018).

32. Han, S. et al. Evaluation of regional background particulate matter concentration based on vertical distribution characteristics. Atmos. Chem. Phys. 15, 11165-11177 (2015).

33. Kulmala, M. China's choking cocktail. Nature 526, 497-499 (2015).

34. Kulmala, M. et al. Is reducing new particle formation a plausible solution to mitigate particulate air pollution in Beijing and other Chinese megacities? Faraday Discuss. https://doi.org/10.1039/d0fd00078g (2020).

35. Du, W. et al. Simultaneous measurements of particle number size distributions at ground level and $260 \mathrm{~m}$ on a meteorological tower in urban Beijing, China. Atmos. Chem. Phys. 17, 6797-6811 (2017).

36. Sun, Y. et al. Real-time characterization of aerosol particle composition above the urban canopy in Beijing: insights into the interactions between the atmospheric boundary layer and aerosol chemistry. Environ. Sci. Technol. 49, 11340-11347 (2015).

37. Maso, D. M. et al. Formation and growth of fresh atmospheric aerosols: eight years of aerosol size distribution data from SMEAR II, Hyytiala, Finland. Boreal Environ. Res. 10, 323-336 (2005).

38. Kulmala, M. et al. On the formation, growth and composition of nucleation mode particles. Tellus B Chem. Phys. Meteorol. 53, 479-490 (2001).

39. Reutter, P. et al. Aerosol- and updraft-limited regimes of cloud droplet formation: influence of particle number, size and hygroscopicity on the activation of cloud condensation nuclei (CCN). Atmos. Chem. Phys. 9, 7067-7080 (2009).

40. Chen, $X$. et al. Improving new particle formation simulation by coupling a volatility-basis set (VBS) organic aerosol module in NAQPMS+APM. Atmos. Environ. 204, 1-11 (2019).

41. Wang, Z. et al. A deflation module for use in modeling long-range transport of yellow sand over east asia. J. Geophys. Res. 105, 26947-26960 (2000).

42. Yu, F. \& Luo, G. Simulation of particle size distribution with a global aerosol model: contribution of nucleation to aerosol and ccn number concentrations. Atmos. Chem. Phys. 9, 7691-7710 (2009).

43. $\mathrm{Du}, \mathrm{H}$. et al. Modeling of aerosol property evolution during winter haze episodes over a megacity cluster in northern China: Roles of regional transport and heterogeneous reactions. Atmos. Chem. Phys. 19, 9351-9370 (2019).

44. Chen, X. et al. Development of a regional chemical transport model with sizeresolved aerosol microphysics and its application on aerosol number concentration simulation over China. Sci. Online Lett. Atmos. 10, 83-87 (2014).

45. Chen, $X$. et al. Simulation on different response characteristics of aerosol particle number concentration and mass concentration to emission changes over mainland china. Sci. Total Environ. 643, 692-703 (2018).

\section{ACKNOWLEDGEMENTS}

This work is supported by the National Natural Science Foundation of China (91744207), the National Key R\&D Program of China (2017YFC0212704), Academy of Finland via Center of Excellence in Atmospheric Sciences (project no. 272041) and European Research Council via ATM-GTP (project no. 742206). This research has also received funding from Academy of Finland (project no. 316114, 315203 \& 311932), trans-national ERA-PLANET project SMURBS (Grant Agreement 689443) under the EU Horizon 2020 Framework Programme, as well as the Doctoral Program in
Atmospheric Sciences at the University of Helsinki. Partial support from the National Key R\&D Program of China (2017YFC0209503 \& 2017YFC0209505), the National Science Foundation of China (21876094), and the National Natural Science Foundation of China (91644213 \&41730106) is acknowledged. Moreover, this research received support from the Swiss National Science postdoc mobility grant (P2EZP2_181599). This publication has been produced within the framework of the EMME-CARE project, which has received funding from the European Union's Horizon 2020 Research and Innovation Programme (under grant agreement no. 856612) and the Government of Cyprus. The sole responsibility of this publication lies with the author. The European Union is not responsible for any use that may be made of the information contained therein.

\section{AUTHOR CONTRIBUTIONS}

W.D. and L.D. wrote the paper. W.D., L.D., and J.Z. analyzed the data. X.-S.C. and Z.-F.W. performed the model analysis. W.D., J.Z., C.-H.X., W.-G.W., Y.H., Y.-J.Z., Q.-Q.W., W.-Q.X., Y.-Y. W., G.-Q.T., X.-L.C., and W.Z. performed the measurements. W.D., L.D., J.Z., K.R.D., X.-S.C., J.C., L.Y., T.V.K., C.Y., B.-W.C., Q.-Z.Z., S.H., M.K., L.J., Y.-C.L., Z.-Q.L., M.-F.G., P.-Q.F., W.N., P.P., D.R.W., V.-M.K., M.K., and Y.-L.S. interpreted the results and revised the manuscript. Y.-L.S. designed this study. M.K. and Y.-L.S. supported and supervised this research. All authors reviewed and commented on the paper. W.D. and L.D. contributed equally to this paper.

\section{COMPETING INTERESTS}

The authors declare no competing interests.

\section{ADDITIONAL INFORMATION}

Supplementary information is available for this paper at https://doi.org/10.1038/ s41612-020-00156-5.

Correspondence and requests for materials should be addressed to M.K. or Y.S.

Reprints and permission information is available at http://www.nature.com/ reprints

Publisher's note Springer Nature remains neutral with regard to jurisdictional claims in published maps and institutional affiliations.

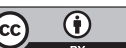

Open Access This article is licensed under a Creative Commons Attribution 4.0 International License, which permits use, sharing, adaptation, distribution and reproduction in any medium or format, as long as you give appropriate credit to the original author(s) and the source, provide a link to the Creative Commons license, and indicate if changes were made. The images or other third party material in this article are included in the article's Creative Commons license, unless indicated otherwise in a credit line to the material. If material is not included in the article's Creative Commons license and your intended use is not permitted by statutory regulation or exceeds the permitted use, you will need to obtain permission directly from the copyright holder. To view a copy of this license, visit http://creativecommons. org/licenses/by/4.0/.

(c) The Author(s) 2021 